\title{
Accelerator mass spectrometry of the actinides
}

\author{
L.K. Fifield* \\ Department of Nuclear Physics, Research School of Physical Sciences and Engineering, The Australian National University, Canberra, ACT 0200, Australia
}

Received 15 May 2007; received in revised form 17 October 2007; accepted 20 October 2007

Available online 22 November 2007

\begin{abstract}
Accelerator mass spectrometry (AMS) is presently the most sensitive technique for the measurement of actinides with half-lives greater than about 5000 years. Here, the principles and methodology of heavy-element AMS as applied to ${ }^{239,240,242,244} \mathrm{Pu}$ and ${ }^{236} \mathrm{U}$ are described, and the ways in which these have been implemented in various laboratories around the world are detailed. Actual or potential applications of the method in the areas of environmental science, biomedicine, and nuclear safeguards are reviewed.
\end{abstract}

(C) 2007 Elsevier Ltd. All rights reserved.

Keywords: Plutonium; Uranium-236; Accelerator mass spectrometry

\section{Introduction}

Anthropogenic $\alpha$-particle emitting nuclides with halflives that are long relative to the human life-span have been released into the environment by nuclear testing, nuclear accidents and reprocessing operations. Among the most significant are ${ }^{239,240} \mathrm{Pu}$ and ${ }^{236} \mathrm{U}$. Quantifying the releases, and tracing their subsequent dispersal has traditionally been the task of $\alpha$-particle counting or, more recently, of thermal ionization or inductively-coupled plasma (ICP) mass spectrometers. Although these are mature methodologies, each has its limitations. These limitations are largely surmounted by the relatively new technique of accelerator mass spectrometry (AMS).

For realistic counting times, $\alpha$-particle counting is limited in sensitivity to an activity of $\sim 50 \mu \mathrm{Bq}$ (O'Donnell et al., 1997). Counting times required for sensible results at this level are $\geqslant 4$ weeks. For ${ }^{239} \mathrm{Pu}$, the limit corresponds to $20 \mathrm{fg}$. In addition, $\alpha$-particle counting is unable to resolve the two most important plutonium isotopes, ${ }^{239} \mathrm{Pu}$ and ${ }^{240} \mathrm{Pu}$, because their $\alpha$-particle energies differ by only $11 \mathrm{keV}$ in $5.25 \mathrm{MeV}$. Hence, information on the ${ }^{240} \mathrm{Pu} /{ }^{239} \mathrm{Pu}$ ratio, which is a useful indicator of the source of the plutonium, is not available.

\footnotetext{
*Tel.: + 6126125 2095; fax: + 61261250748 .

E-mail address: keith.fifield@anu.edu.au
}

Mass-spectrometric methods do give information on the ${ }^{240} \mathrm{Pu} /{ }^{239} \mathrm{Pu}$ ratio, and potentially have higher sensitivity than $\alpha$-particle counting, with values as low as $\sim 1$ fg having been reported, but are sensitive to molecular interferences (Wyse et al., 2001). For example, ${ }^{238} \mathrm{UH},{ }^{208} \mathrm{~Pb}^{31} \mathrm{P}$, etc. could interfere with measurement of ${ }^{239} \mathrm{Pu}$.

Accelerator mass spectrometry combines the highsensitivity of the mass-spectrometric methods with a high level of discrimination against molecular interferences. The means of achieving this are described in detail later. Applications of the method are presented in subsequent sections.

\section{Principles of AMS as applied to heavy radionuclides}

\subsection{Plutonium isotopes}

Accelerator mass spectrometry measures an isotope ratio, which would be ${ }^{14} \mathrm{C} /{ }^{12} \mathrm{C}$ in the most familiar example of radiocarbon AMS. In conventional AMS, the radioactive isotope $\left({ }^{14} \mathrm{C}\right)$ is measured by ion counting, while the hugely more abundant stable isotope $\left({ }^{12} \mathrm{C}\right)$ can be readily measured as an electric current.

In the case of plutonium, there is no stable isotope. Hence, it is necessary to add a "spike" of a known amount of one of the long-lived isotopes, generally ${ }^{242} \mathrm{Pu}$, to the 


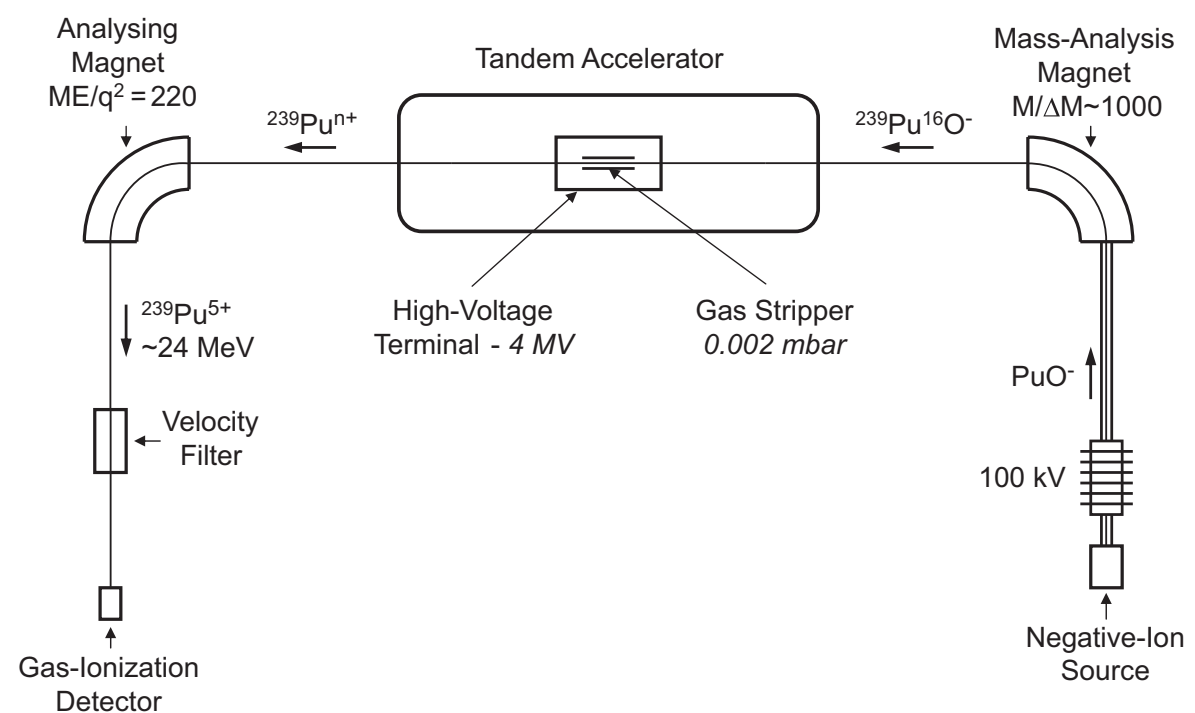

Fig. 1. Essential features of an AMS system for the measurement of Pu.

sample in order to quantify the concentrations of the isotopes of interest, which may be either ${ }^{239,240} \mathrm{Pu}$ or ${ }^{244} \mathrm{Pu}$. Both cost and radiological issues dictate that the amount of spike added is in the range $1-10 \mathrm{pg}$ rather than the milligram quantities of element that are used in conventional AMS. Consequently, both the isotopes of interest and the ${ }^{242} \mathrm{Pu}$ spike must be measured by ion counting (Fifield et al., 1997, 1996).

Fig. 1 shows the basic elements of the AMS system at the Australian National University (ANU) as configured for $\mathrm{Pu}$. It consists essentially of two spectrometers separated by an accelerator that serves as a molecular dissociator. Its basic features are as follows:

1. A low-energy mass spectrometer consisting of a negative ion source and a mass-analysing magnet.

2. Acceleration of the molecular negative ions to the positive high-voltage terminal of a tandem electrostatic accelerator.

3. Dissociation of the molecules and removal of electrons by a low-pressure gas to produce positive plutonium ions.

4. Acceleration of the positive ions back to ground potential, followed by a second spectrometer that selects plutonium ions in a particular charge state with a welldefined energy.

5. A detection system that positively identifies each individual $\mathrm{Pu}$ ion and rejects any remaining background ions.

\subsection{Uranium-236}

AMS of ${ }^{236} \mathrm{U}$ is more conventional in that a ${ }^{238} \mathrm{U}$ beam that is sufficiently large to measure as a current in a Faraday cup is generally available. Hence, only the ${ }^{236} \mathrm{U}$ ions must be measured by ion counting. Due to the fact that ${ }^{235} \mathrm{U}$ and ${ }^{238} \mathrm{U}$ are of necessity abundant in the sample and hence are a potent source of background, the detection system is more complex than for plutonium, and incorporates a high-resolution velocity measurement by time-offlight (TOF) in addition to the energy measurement.

\section{Advantages of AMS relative to conventional mass spectrometry}

Both ${ }^{236} \mathrm{U}$ and plutonium isotopes have been measured by conventional mass spectrometry, using either thermalionization (TIMS) or inductively-coupled plasma (ICPMS) positive ion sources.

For plutonium isotopes, abundance sensitivity is not a problem for conventional mass spectrometry due to the absence of a relatively intense beam of similar mass. Molecular interferences such as ${ }^{238} \mathrm{UH},{ }^{208} \mathrm{~Pb}^{31} \mathrm{P}$, etc. may be a problem, however. These can be at least partially overcome with a high-resolution magnetic sector instrument, and sensitivities at the fg level have been reported for modern high-resolution ICP-MS systems that employ a secondary electron multiplier to count the plutonium ions (Wyse et al., 2001). Nevertheless, AMS offers advantages in terms of immunity to molecular interferences which might go unrecognized in a conventional system, and sensitivities at the $0.1 \mathrm{fg}$ level have been achieved (Brown et al., 2004; Fifield et al., 1997, 1996).

For uranium, outputs from TIMS and ICP ion sources are in the range of $10-100 \mathrm{pA}$ of ${ }^{238} \mathrm{U}\left(\sim 10^{8}-10^{9}\right.$ ions/s). Hence, at a ${ }^{236} \mathrm{U} /{ }^{238} \mathrm{U}$ ratio of $10^{-10}$, which is at the upper end of the ratios found naturally in high grade uranium ores, the flux of ${ }^{236} \mathrm{U}$ ions would be only $0.01-0.1 \mathrm{~s}^{-1}$. At these low counting rates, it is necessary to use a secondary electron multiplier to count the ${ }^{236} \mathrm{U}$ ions. Background under the ${ }^{236} \mathrm{U}$ peak arises from the ${ }^{235} \mathrm{UH}$ molecule or other molecules of mass 236, and from the tail of the ${ }^{238} \mathrm{U}$ 
beam. The best reported $\mathrm{UH}^{+} / \mathrm{U}^{+}$ratios from ICP sources are $2-3 \times 10^{-6}$ (Ketterer et al., 2003). Hence the ${ }^{235} \mathrm{UH}$ contribution at mass-236 corresponds to a ${ }^{235} \mathrm{UH} /{ }^{238} \mathrm{U}$ ratio of $2 \times 10^{-8}$. Further, the low-energy tail of the intense ${ }^{238} \mathrm{U}$ beam is $\sim 10^{-6}$ of the main peak (Ketterer et al., 2003). Variability in both the molecular and tail contributions limits the sensitivity of ICP-MS to ${ }^{236} \mathrm{U} /{ }^{238} \mathrm{U}$ ratios of $\sim 10^{-7}$. TIMS ion sources, on the other hand, produce much lower molecular beams, and a decelerating lens after magnetic analysis can reduce the ${ }^{238} \mathrm{U}$ tail to a negligible level. Background is then dominated by the dark noise of the electron multiplier and by scattered lighter-mass ions. Richter et al. (1999) report background counting rates of $10^{-2} \mathrm{~s}^{-1}$ and a sensitivity of $1 \times 10^{-10}$ in the ${ }^{236} \mathrm{U} /{ }^{238} \mathrm{U}$ ratio.

In contrast to the lower currents available from TIMS and ICP sources, negative ion outputs from sputter sources are $100 \mathrm{nA}$ or more of ${ }^{238} \mathrm{UO}^{-}$, and even given typical transmission of $3 \%$, still represent $2 \times 10^{10238} \mathrm{U}$ ions/s after acceleration. Hence, sufficient counts of ${ }^{236} U$ can be acquired to allow measurement of ratios as low as $\sim 10^{-12}$ provided that backgrounds are suitably low. At a ratio of $10^{-12},{ }^{236} \mathrm{U}$ ions would be detected at a rate of about 1 count per minute. The ${ }^{235} \mathrm{U}^{17} \mathrm{O}$ or ${ }^{238} \mathrm{U}^{14} \mathrm{~N}$ molecular interferences, as well as other more exotic molecular interferences involving lighter elements such as ${ }^{133} \mathrm{Cs}^{107} \mathrm{Ag}^{12} \mathrm{C}$, are broken up in the stripper of the AMS system, and any backgrounds arising from the very small fraction of fragments that pass the subsequent analysis system are readily discriminated by the detection system at the high energies pertaining after acceleration.

\section{Advantages of AMS relative to $\alpha$-particle spectroscopy}

$\alpha$-Particle spectroscopy has been widely used for measuring plutonium concentrations, particularly for tracing releases from nuclear-fuel reprocessing facilities. The limit to its sensitivity is imposed by realistic counting times relative to the half-lives of the isotopes. Assuming a maximum counting time of 1 month, and a typical ${ }^{240} \mathrm{Pu} /{ }^{239} \mathrm{Pu}$ ratio of $20 \%$, only $2 \times 10^{-6}$ of the atoms would decay in this time. Since the (geometric) efficiency of detection is $\sim 0.3$, fewer than one in a million of the $\mathrm{Pu}$ atoms in the sample will be detected. Realistically, the sensitivity limit is $\sim 50 \mu \mathrm{Bq}$ (O'Donnell et al., 1997) or $5 \times 10^{7}$ atoms. AMS is at least two orders of magnitude more sensitive.

An additional limitation of $\alpha$-particle spectroscopy is that the measurement yields only the sum of the ${ }^{240} \mathrm{Pu}$ and ${ }^{239} \mathrm{Pu}$ activities, but not the ${ }^{240} \mathrm{Pu} /{ }^{239} \mathrm{Pu}$ ratio. Since the $\alpha$ particle energies of the decays of the two isotopes differ by only $11 \mathrm{keV}$ in $5.2 \mathrm{MeV}$, the two peaks are not resolved at typical detector energy resolutions of $25-40 \mathrm{keV}$. It is possible to deduce some information from centroid shifts, but since centroids are sensitive to details of sample deposition on the stainless steel disks employed, this method is imprecise at best.
The $20 \mathrm{Ma}$ half-life of ${ }^{236} \mathrm{U}$ limits the utility of $\alpha$-particle spectroscopy for this isotope. A realistic sensitivity limit of $\sim 50 \mu \mathrm{Bq}$ corresponds to $5 \times 10^{10}$ atoms. Limited use of the technique has been made, for example, to search for the presence of depleted uranium resulting from the use of depleted uranium weaponry in Kosovo (Desideri et al., 2002).

\section{Disadvantages of AMS relative to other techniques}

Although AMS has advantages over the other techniques for ${ }^{239,240,242,244} \mathrm{Pu}$, there are two other isotopes, ${ }^{238} \mathrm{Pu}$ and ${ }^{241} \mathrm{Pu}$, which are of interest in some applications. Of these, ${ }^{238} \mathrm{Pu}$ cannot be measured by AMS or other mass spectrometric methods due to interference from natural ${ }^{238} \mathrm{U}$, which is always present in the ion source and/or in the sample itself despite the best efforts of the chemist. Hence, ${ }^{238} \mathrm{Pu}$ can be measured only with $\alpha$-particle spectrometry. The $\beta$-emitter ${ }^{241} \mathrm{Pu}$ can be measured with either AMS or with liquid scintillation counting. Its short half-life of $\sim 14$ years results, however, in higher sensitivity for the latter. Finally, there is a significant increase in complexity, and cost, from $\alpha$-particle spectrometers to mass spectrometers, and to AMS systems.

\section{Details of AMS methodology}

\subsection{Negative ion production and analysis}

The $\mathrm{PuO}^{-}$or $\mathrm{UO}^{-}$molecular ions are selected because their intensities are about two orders of magnitude higher than the $\mathrm{Pu}^{-}$or $\mathrm{U}^{-}$atomic ions. A high-resolution $(M /$ $\Delta M \geqslant 300$ ) magnet is required to separate neighboring masses effectively, particularly ${ }^{238} \mathrm{UO}$ from ${ }^{239} \mathrm{PuO}$.

In the case of plutonium, only picogram quantities of the element are available, whereas the Cs sputter ion sources that are employed in AMS require typical sample masses of $1-10 \mathrm{mg}$. The extra bulk is achieved by dispersing the plutonium in an iron oxide matrix, and mixing it with aluminum or silver powder to ensure electrical and thermal conductivity.

Samples for ${ }^{236} \mathrm{U}$ analyses are in the form of uranium oxide which again is mixed with aluminum or silver powder. Beam currents of $100 \mathrm{nA}$ of $\mathrm{UO}^{-}$ions $\left(6 \times 10^{11}\right.$ ions/s) are readily extracted from a uranium oxide sample. In some applications, particularly in the safeguards area, only very small amounts of uranium are available. In these cases, the sample must be bulked with iron oxide (Hotchkis et al., 2000b; Marsden et al., 2001).

The question of efficiency of negative ion formation and extraction in these sources is taken up under the discussion of sensitivity.

\subsection{Acceleration, stripping, and high-energy analysis}

Accelerators operating at $0.3-12.5 \mathrm{MV}$ have been variously employed at different laboratories. 
Dissociation of the negative molecular ions and stripping to positive atomic ions in the high-voltage terminal is generally effected by low-pressure oxygen or argon gas, although very thin carbon foils are employed at the Munich laboratory. After the second stage of acceleration, ions in a single charge state with a well-defined energy are selected by a large magnet or electrostatic analyzer.

At those laboratories employing magnetic analysis, the accelerating voltage is invariably limited by the combination of the bending power of the magnet and the charge state probability distribution. At the ANU 14UD Pelletron accelerator, for example, the $90^{\circ}$ analyzing magnet can bend ions with $M E / q^{2}$ up to $220 \mathrm{MeV}$-amu. Here $M$ is the mass of the ion in amu, $E$ is the energy in $\mathrm{MeV}$, and $q$ is the charge on the ion in units of the electronic charge. In this case, the optimal compromise between transmission and stability is to analyze $\mathrm{Pu}^{5+}$ or $\mathrm{U}^{5+}$ ions. The maximum energy is then $\sim 23 \mathrm{MeV}$ which is achieved at an accelerating voltage of only $\sim 4 \mathrm{MV}$ (Fifield et al., 1996). This is well below the 11-14 MV at which the accelerator runs best, and requires that $\sim 60 \%$ of the accelerator be shorted out. The considerations that determine this choice of charge state and hence of accelerating voltage are as follows:

- The stripping yield drops off rapidly with increasing charge state. For example, the yield in the $6^{+}$charge state is a factor of 2 less than in the $5^{+}$, even allowing for the fact that it is possible to use a higher accelerating voltage of $\sim 4.8 \mathrm{MV}$ at the higher charge state.

- Although the stripping yield to the $4^{+}$charge state is higher than that of the $5^{+}$, it would be necessary to operate the accelerator at $\sim 3 \mathrm{MV}$ in order that the ions could pass around the analyzing magnet. Because transmission through the accelerator is lower at this lower voltage, there is no net gain in using the lower charge state. There would, however, be advantages to using the lower charge states at smaller accelerators provided that the analyzing magnet is sufficiently powerful to bend them.

Equivalent considerations apply to the other laboratories where actinide AMS is practiced, but play out differently depending on the available hardware. Laboratory-specific details will be taken up later.

\subsection{Final analysis and detection}

Following the analyzing magnet, it is usual to have an additional analysis that involves an electric field. This may be either an electrostatic analyzer (ESA) or a velocity filter. The latter, also known as a Wien filter, employs crossed electric and magnetic fields to allow only ions with a definite velocity to pass undeflected. Since the analyzing magnet selects ions of constant $M E / q^{2}$, and an ESA or Wien filter selects ions of constant $E / q$ or velocity $(E / M)$, respectively, the combination of the two selects only ions which have the same $M / q$. An ESA with a $90^{\circ}$ deflection angle has higher resolution than a Wien filter, but the latter has the advantage that it is simpler to align and can be turned off to tune the beam.

Detectors fall into different categories, depending on the species to be detected.

For $\mathrm{Pu}$, backgrounds from uranium tend to be low because uranium concentrations in the sample can be reduced to very low levels with appropriate chemistry. If uranium background is negligible, then the detector has only to discriminate between $\mathrm{Pu}$ ions and lower-energy ions in lower charge states. To take a specific example, if $\mathrm{Pu}^{5+}$ ions are selected, the only background ions that reach the detector are $4^{+}, 3^{+}, 2^{+}$and $1^{+}$ions that have the same $M /$ $q$ as the plutonium. Since these have $4 / 5,3 / 5,2 / 5$ and $1 / 5$ of the plutonium energy respectively, a simple energy measurement is usually all that is required to discriminate them from the $\mathrm{Pu}^{5+}$ ions. An ionization chamber is the detector of choice on the basis of robustness and adequate energy resolution, although silicon detectors have also been employed.

For ${ }^{236} \mathrm{U}$ on the other hand, the sample contains unavoidably high levels of ${ }^{238} \mathrm{U}$ and ${ }^{235} \mathrm{U}$, which are potent sources of background, even in an AMS system. The origins of these backgrounds will be discussed in more detail below, but it is sufficient to acknowledge at this point that even with a high-resolution ESA or Wien filter, there are inescapable backgrounds of ${ }^{238} \mathrm{U}$ and ${ }^{235} \mathrm{U}$ ions that limit the sensitivity of the ${ }^{236} \mathrm{U} /{ }^{238} \mathrm{U}$ ratio to $\sim 10^{-8}$ to $10^{-9}$ if they are not resolved from ${ }^{236} \mathrm{U}$. An ionization chamber does not have sufficient energy resolution to separate the three uranium isotopes since the energies of the ${ }^{238} \mathrm{U}$ and ${ }^{235} \mathrm{U}$ ions differ by only $-0.8 \%$ and $0.4 \%$, respectively, from the ${ }^{236} \mathrm{U}$ ions. In order to achieve the required resolution, TOF systems with a flight path of $\sim 2 \mathrm{~m}$ have therefore been employed. An energy measurement is still required to separate the ${ }^{236} \mathrm{U}$ ions from the lower energy ions with the same $M / q$, since these have the same velocity and hence the same flight time as the ${ }^{236} \mathrm{U}$ ions.

\subsection{Ionization chambers}

At the ANU, propane is employed as the detector gas at a pressure of 55 Torr, and the $23 \mathrm{MeV}$ ions pass into the detector through a $0.7 \mu \mathrm{m}$ mylar window with a diameter of $13 \mathrm{~mm}$, losing $\sim 3 \mathrm{MeV}$ or $13 \%$ of their energy in the process. Typical energy spectra are shown in Fig. 2. A resolution $\Delta E / E=3 \%$ is achieved for $23 \mathrm{MeV}$ plutonium ions, which is clearly adequate to separate plutonium from lighter-mass, lower-charge state ions.

An ionization detector is also used by the Zurich group (Wacker et al., 2005), but to detect plutonium ions with an energy of only $1.2 \mathrm{MeV}$. A silicon nitride membrane with a thickness of $40 \mathrm{~nm}$ and an area of $3 \times 3 \mathrm{~mm}^{2}$ retains the isobutane gas at a typical pressure of $15 \mathrm{mbar}$. These ultrathin silicon nitride membranes were crucial to this application since $1.2 \mathrm{MeV}$ plutonium ions would stop in the thinnest available mylar $(0.5 \mu \mathrm{m})$ but lose only $30 \%$ of 


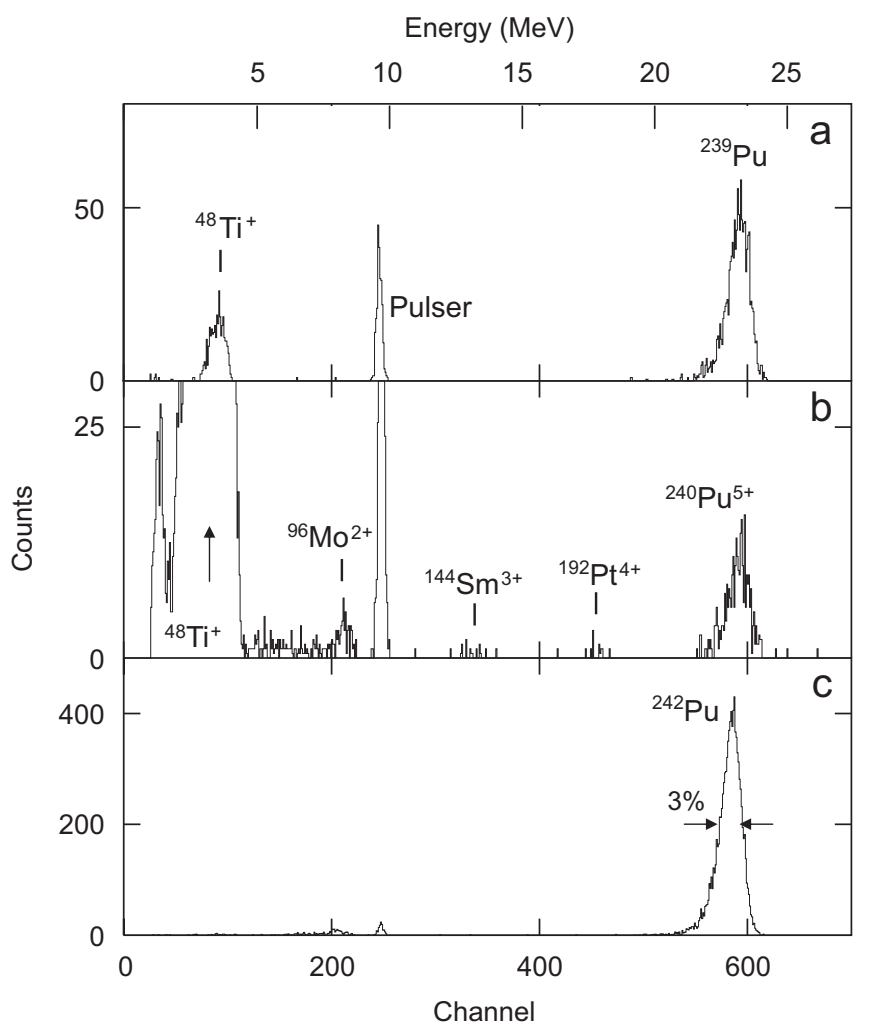

Fig. 2. Energy spectra from the ionization chamber for (a) ${ }^{239} \mathrm{Pu}$, (b) ${ }^{240} \mathrm{Pu}$, and (c) ${ }^{242} \mathrm{Pu}$ from a surface soil sample. A spike of $4 \mathrm{pg}$ of ${ }^{242} \mathrm{Pu}$ was added to the sample for normalization purposes. Acquisition times were 2, 3 and $1 \mathrm{~min}$, respectively. The pulser served to monitor dead-time in the electronics and data acquisition system. Note that the ${ }^{240} \mathrm{Pu}$ spectrum in particular shows peaks at lower energy that arise from fragments of molecules that were dissociated in the gas stripper and subsequently passed the high-energy analysis. These are identified by atomic species, isotope and charge state. Events that fall between the intense ${ }^{48} \mathrm{Ti}$ peak and the ${ }^{96} \mathrm{Mo}$ peak are due to pile-up of two ${ }^{48} \mathrm{Ti}$ ions that arrive within the resolving time of the detector electronics. Careful inspection of the $\mathrm{Pu}$ peaks reveals the expected small centroid shifts from one isotope to the next.

their energy in the silicon nitride. Resolution of the ion chamber with a $40 \mathrm{~nm}$ silicon nitride window is $\sim 20 \%$ of the signal height (Suter et al., 2007). Typical spectra which contrast the performance of a silicon detector and a lownoise ion chamber with two different thicknesses of silicon nitride window are shown in Fig. 3 (Wacker et al., 2005).

\subsection{Time-of-flight systems}

TOF systems for AMS consist of "start" and "stop" detectors typically separated by $2 \mathrm{~m}$, and also incorporate a measurement of the ion's energy.

Start detectors must transmit the ions, and hence are all based on the collection of electrons liberated from a thin carbon foil as the ions pass through it. The electrons are accelerated to typically $1 \mathrm{keV}$, and transported isochronously to a micro-channel plate (MCP) assembly (Starzecki et al., 1982). MCPs may be operated at very high gain of a

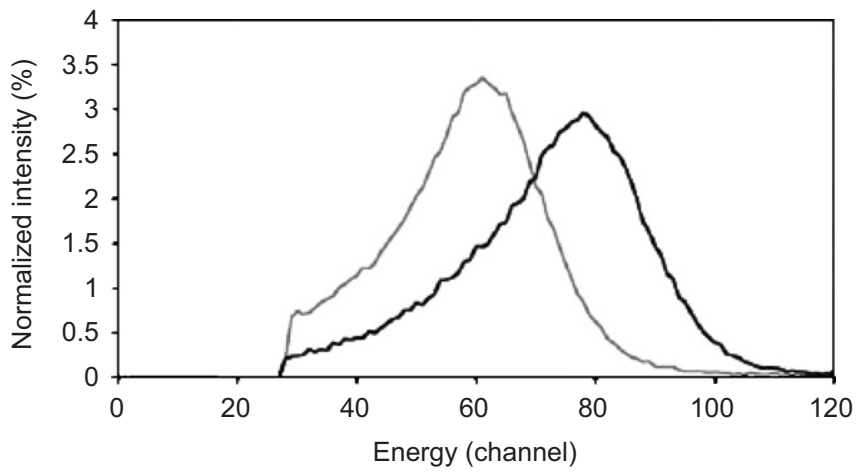

b

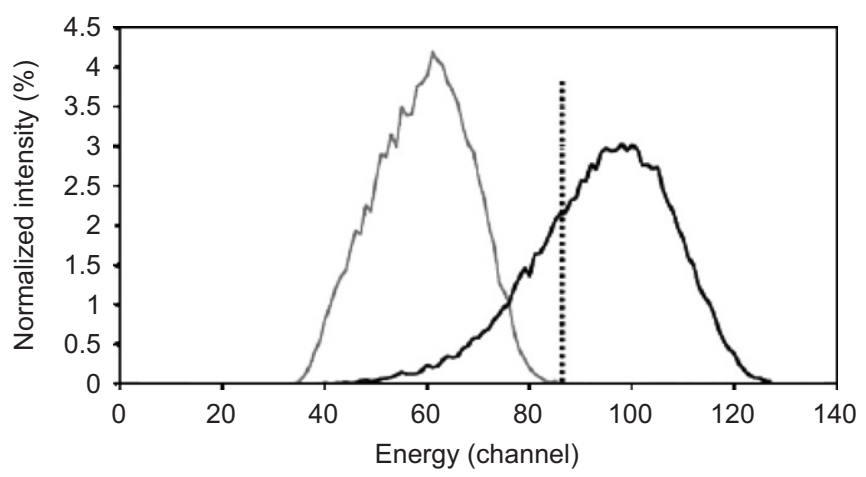

C

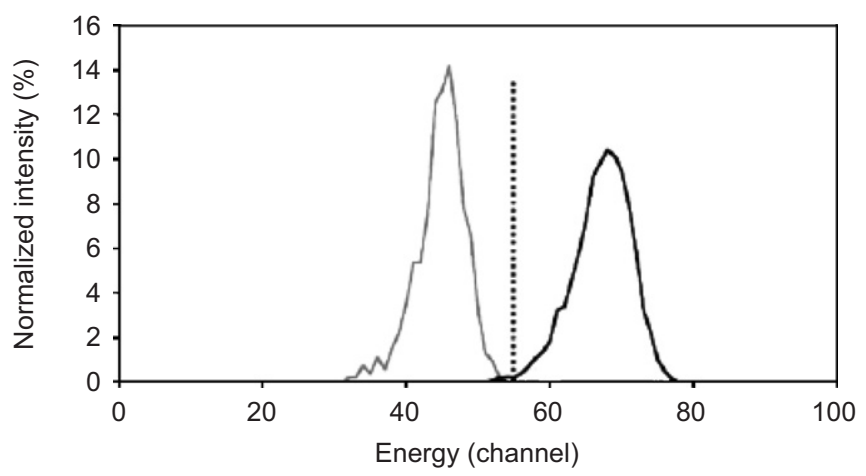

Fig. 3. The spectra obtained from (a) a surface barrier detector, (b) a gas ionization detector with a $100 \mathrm{~nm} \mathrm{Si-N}$ window and (c) a gas ionization detector with a $40 \mathrm{~nm} \mathrm{Si-N}$ window are shown, for $1.2 \mathrm{MeV}{ }^{240} \mathrm{Pu}^{3+}$ (black line) or $0.8 \mathrm{MeV}^{160} \mathrm{Dy}^{2+}$ (gray line) ions. The dotted line marks the low level discriminator to cut off virtually all $2^{+}$ions. From Wacker et al. (2005).

$\sim 10^{7}$, and produce very fast output pulses with rise times of $\sim 1$ ns that are ideal for fast-timing applications. In order to minimize losses of ions due to scattering, the carbon foils should be as thin as possible. Diamond-like carbon foils as thin as $0.5 \mu \mathrm{g} / \mathrm{cm}^{2}$ (Liechtenstein et al., 2004) are now widely used, although they must be supported on a copper mesh with a transparency of only $75 \%$.

The stop detector may be either a silicon detector, in which case it also provides the measurement of the ion's energy, or another MCP detector. In order to collect as many as possible of the ions that passed through the start detector, active areas of at least $25 \mathrm{~mm}$ in diameter are 
advantageous. If the MCP option is adopted, then it must be followed by either an ionization chamber or silicon detector to provide the energy information.

Although intrinsic resolutions of $0.3-0.4 \mathrm{~ns}$ have been reported for such TOF systems (Steier et al., 2002), in practical situations the observed resolution is generally about $1 \mathrm{~ns}$. As can be seen from Table 1, this resolution is sufficient to separate ${ }^{236} \mathrm{U}$ from ${ }^{235} \mathrm{U}$ and ${ }^{238} \mathrm{U}$ ions of the same magnetic rigidity provided that count rates of the latter are low. This is illustrated by Fig. 4, which shows a two-dimensional plot of energy vs TOF and the onedimensional projection on to the TOF axis for a sample with ${ }^{236} \mathrm{U} /{ }^{238} \mathrm{U}=6 \times 10^{-11}$.

A drawback of a TOF system is that its efficiency is typically only $30-50 \%$ due both to losses on the multiple grids and foil-supporting meshes of the start and stop detectors, and to losses due to beam divergence and scattering in the foil of the start detector.

Table 1

Flight times over a $2 \mathrm{~m}$ flight path for $5^{+}$uranium ions of different masses but the same magnetic rigidity

\begin{tabular}{lllc}
\hline Ion & Energy $(\mathrm{MeV})$ & Flight time, $T(\mathrm{~ns})$ & $\Delta T(\mathrm{~ns})$ \\
\hline${ }^{235} \mathrm{U}$ & 23.995 & 518.3 & -2.2 \\
${ }^{236} \mathrm{U}$ & 23.893 & 520.5 & \\
${ }^{238} \mathrm{U}$ & 23.692 & 525.0 & 4.4 \\
\hline
\end{tabular}

Energies are typical of those used at the ANU.

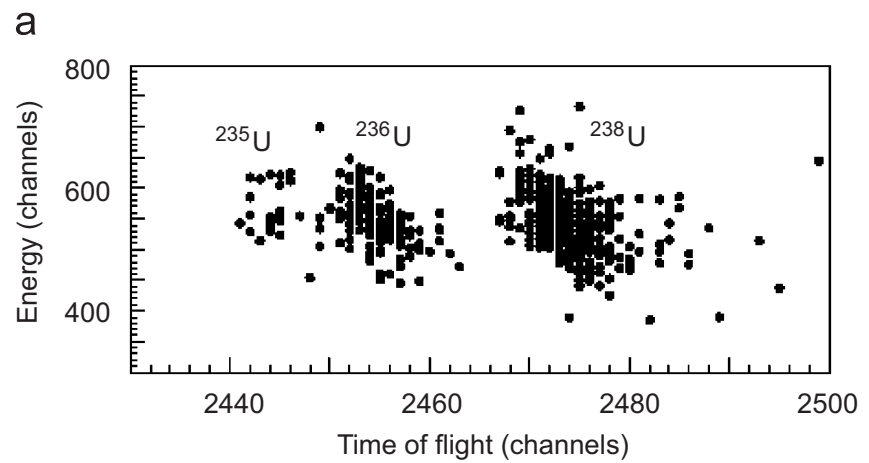

b

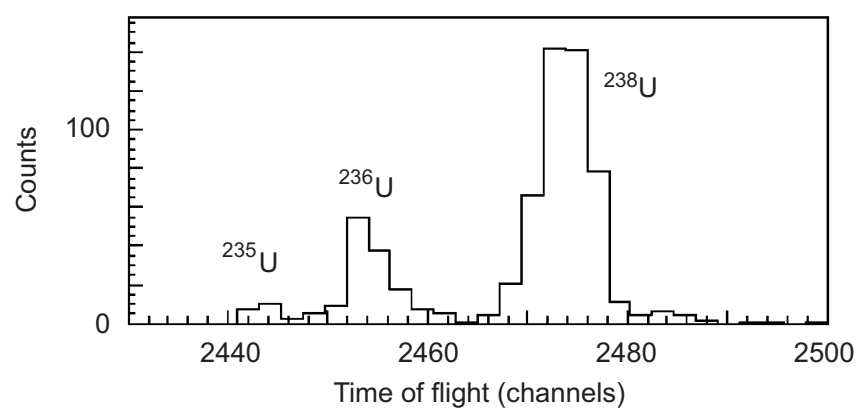

Fig. 4. (a) Two-dimensional spectrum of energy deposited in the $\mathrm{Si}$ detector vs TOF for a uranium ore sample with a ${ }^{236} \mathrm{U} /{ }^{238} \mathrm{U}$ ratio of $6 \times 10^{-11}$. (b) One-dimensional projection of (a) on to the TOF axis.

\section{Implementation at various laboratories}

\subsection{IsoTrace, Toronto}

AMS measurement of actinides, and of ${ }^{236} U$ and plutonium isotopes in particular, were pioneered at the IsoTrace facility. The first detection of ${ }^{236} \mathrm{U}$ in a uranium ore was reported by Zhao et al. (1994a) using the IsoTrace heavy element AMS system at an accelerating voltage of 1.6 $\mathrm{MV}$ and detecting the $5^{+}$ions. In a companion paper (Zhao et al., 1994b), the same authors employed an accelerating voltage of $1.25 \mathrm{MV}$ and detected ${ }^{244} \mathrm{Pu}^{4+}$ ions in order to determine the relative yields of various molecular negative ions of plutonium from a cesiumsputter ion source. Subsequently, ${ }^{236} \mathrm{U}$ measurements were performed on groundwater samples from the US Idaho Chemical Processing Plant (Zhao et al., 1997).

\section{2. $A N U$}

At the ANU, the accelerating voltage of $\sim 4 \mathrm{MV}$ and the choice of the $5^{+}$charge state are dictated by the maximum mass-energy product $(220 \mathrm{MeV}-\mathrm{amu})$ of the $90^{\circ}$ analyzing magnet. A Wien filter is employed to remove backgrounds which have the same $M E / q^{2}$ as the ions of interest but different velocities. Switching between different isotopes is accomplished by changing

(i) the field in the injection magnet,

(ii) the terminal voltage of the accelerator, and

(iii) the electric field of the Wien filter.

Switching times in this slow-cycling procedure are $10 \mathrm{~s}$. For plutonium, measurement times are generally $1 \mathrm{~min}$ at ${ }^{242} \mathrm{Pu}, 3 \mathrm{~min}$ at ${ }^{240} \mathrm{Pu}$ and $2 \mathrm{~min}$ at ${ }^{239} \mathrm{Pu}$. This sequence is repeated as many times as necessary, with three loops being typical. For ${ }^{236} \mathrm{U}$, each loop consists of integration of the ${ }^{238} \mathrm{U}$ beam current for $10 \mathrm{~s}$, and counting of ${ }^{236} \mathrm{U}$ ions for 5 min.

Detection systems are an ionization chamber for ${ }^{239,240,242,244} \mathrm{Pu}$ and a TOF system for ${ }^{236} \mathrm{U}$.

\subsection{Lawrence Livermore National Laboratory}

At Livermore, an analyzing magnet with a deflection angle of only $30^{\circ}$ followed by a $45^{\circ}$ ESA allows the use of a higher terminal voltage of $6.5 \mathrm{MV}$. This arrangement is depicted in Fig. 5. Again, gas-stripping is employed and the $5^{+}$charge state is selected. The detection system for plutonium, ${ }^{237} \mathrm{~Np}$, and ${ }^{236} \mathrm{U}$ is a two-anode longitudinalfield ion chamber (Brown et al., 2004; McAninch et al., 2000).

Switching between isotopes is accomplished with a fastswitching system. Different voltages are applied to the vacuum box of the injection magnet in order to inject the various isotopes into the accelerator. An electrostatic steerer after the $30^{\circ}$ analyzing magnet directs the different 


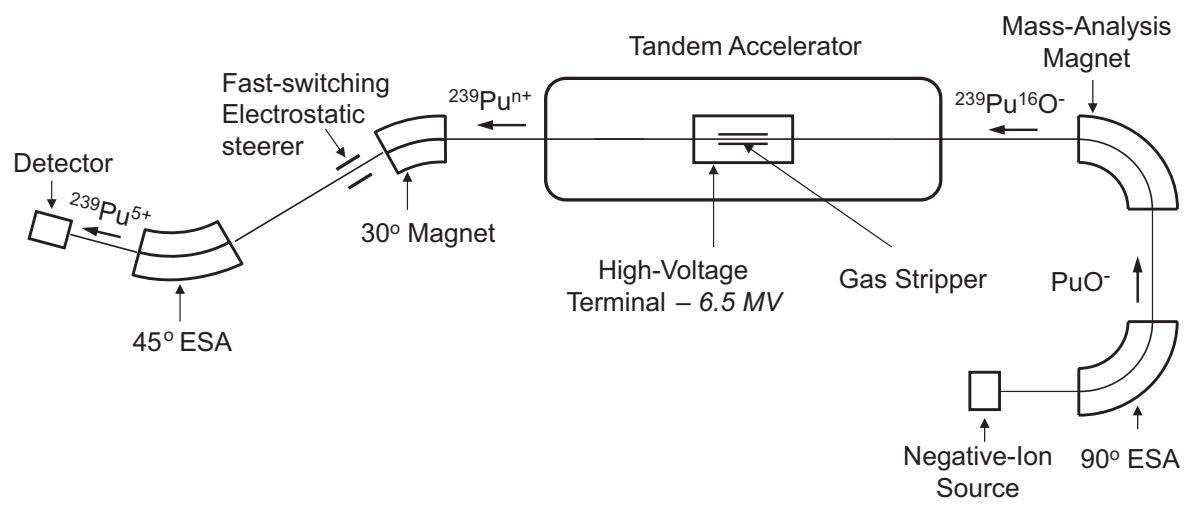

Fig. 5. AMS system for the measurement of actinides at Lawrence Livermore National Laboratory. After Brown et al. (2004).

isotopes through the image slits of the magnet and into the ESA. The all-electric switching can be fast, $\sim 10 \mu \mathrm{s}$. Measurement times are $0.1 \mathrm{~s}$ for ${ }^{242} \mathrm{Pu}$ and $0.4 \mathrm{~s}$ for ${ }^{239} \mathrm{Pu}$ and ${ }^{240} \mathrm{Pu}$. Cycling between the ${ }^{242} \mathrm{Pu}-{ }^{239} \mathrm{Pu}$ pair continues for $10 \mathrm{~s}$ before changing to the ${ }^{242} \mathrm{Pu}-{ }^{240} \mathrm{Pu}$ pair for the next $10 \mathrm{~s}$.

\subsection{ANSTO}

At ANSTO, the accelerating voltage is again $4 \mathrm{MV}$ and the $5^{+}$charge state is selected.

A heavy-element beam-line consisting of a high-resolution, $2.5 \mathrm{~m}$ radius, $90^{\circ}$ ESA followed by a large $(2.0 \mathrm{~m}$ radius) $90^{\circ}$ magnet (Fig. 6) has been constructed to analyze the $\sim 24 \mathrm{MeV}$ heavy ions after acceleration (Hotchkis et al., $2000 \mathrm{a}, \mathrm{b}$ ). The advantage of having the magnet as the final element in the system is that, for a given charge state, it disperses in mass following the $E / q$ selection of the ESA. Hence the focal plane of the magnet can be instrumented at specific locations with various detection systems tailored to the intensity of the isotopes to be measured. An ionization chamber is employed for Pu measurements, and is preceded by a TOF system composed of two micro-channel plate detectors for ${ }^{236} \mathrm{U}$ measurements. The more intense ${ }^{238} \mathrm{U}$, ${ }^{235} \mathrm{U}$ or ${ }^{234} \mathrm{U}$ beams can be measured by either Faraday cups or an electron multiplier, as shown in Fig. 7.

\subsection{VERA}

Despite the lower terminal voltage of $3 \mathrm{MV}$ of the VERA accelerator, the $5^{+}$charge state is selected because this is the minimum charge that the $90^{\circ}$ analyzing magnet can bend (Steier et al., 2002). The yield for stripping ${ }^{238} \mathrm{U}^{16} \mathrm{O}^{-}$ to ${ }^{238} \mathrm{U}^{5+}$ was measured to be $6 \%$. A high-resolution $90^{\circ}$ ESA after the analyzing magnet strongly suppresses ions with different $M / q$ ratios. Any residual background ions are identified by a TOF system consisting of two microchannel plate detectors. This is backed by an ionization chamber to discriminate against lower charge state ions of the same $M / q$. The overall efficiency of the detection system is $20-30 \%$.

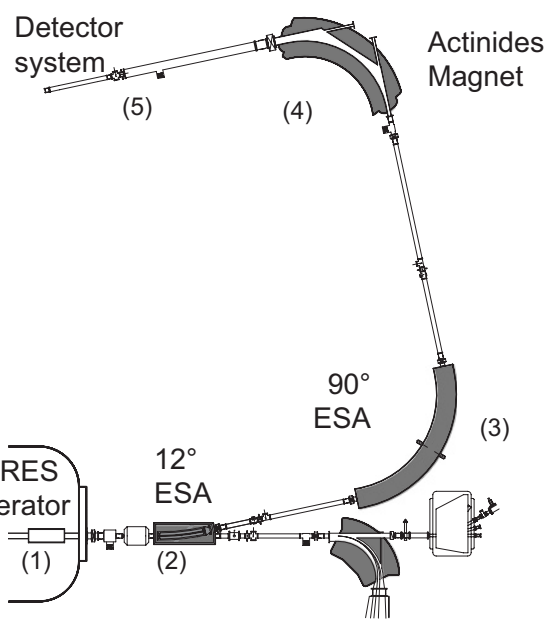

Fig. 6. High-energy actinide beam-line at the ANTARES facility at the Australian Nuclear Science and Technology Organization (ANSTO). Reprinted with permission from Hotchkis et al. (2000a).

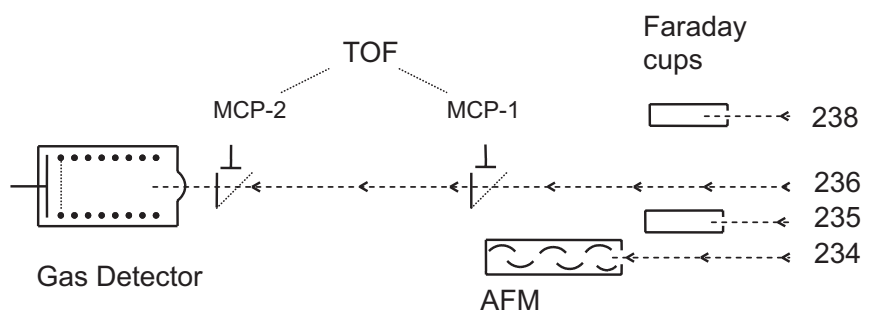

Fig. 7. Detector instrumentation at the focal plane of the high-energy actinide beam-line at ANSTO as in 2000. Reprinted with permission from Hotchkis et al. (2000a). Note that this has subsequently evolved.

A slow-cycling procedure is employed for plutonium analyses. Switching times between isotopes are $15 \mathrm{~s}$ and measurement times range between 20 and $100 \mathrm{~s}$ (Hrnecek et al., 2005; Winkler et al., 2004). For ${ }^{236}$ U, a quasi-fast switching procedure has been adopted. Ion source fluctuations are monitored by fast switching of the ${ }^{238} \mathrm{U}^{16} \mathrm{O}^{-}$ beam into the low-energy off-axis Faraday cup during post-acceleration measurement of both the ${ }^{238} \mathrm{U}$ beam current and ${ }^{236} \mathrm{U}$ ions. Due to the small fractional mass 
difference between ${ }^{238} \mathrm{U}$ and ${ }^{236} \mathrm{U}$, it is, however, necessary to change the accelerator voltage when switching between isotopes at the high-energy side. This takes $\sim 15 \mathrm{~s}$. Hence, the ${ }^{238} \mathrm{U}^{5+}$ beam current is measured only every $5 \mathrm{~min}$. This frequency is quite adequate to monitor drifts in stripping yield (Steier et al., 2002; Vockenhuber et al., 2003).

\subsection{Munich}

The Munich facility is blessed with a very large analyzing magnet with a mass-energy product of $350 \mathrm{MeV}$-amu. This makes the use of foil stripping at a higher terminal voltage a viable option. An accelerating voltage of $12.5 \mathrm{MV}$ is employed, and the $11^{+}$charge state selected. Ions are detected by a TOF system consisting of a MCP "start" detector and a "stop" detector which combines an ionization chamber to provide a $\Delta E$ signal and a silicon detector to provide both the timing signal and a residualenergy signal. Details may be found in (Wallner et al., 2000).

\subsection{ETH, Zurich}

At Zurich, it has been shown that AMS of plutonium can be performed equally well on a small accelerator operating at only $0.3 \mathrm{MV}$ (Fifield et al., 2004; Wacker et al., 2005 ). The $1.2 \mathrm{MeV} \mathrm{Pu}$ ions are analyzed by a combination of $90^{\circ}$ magnetic and electric analyzers, and detected in a gas ionization detector with a 40 or $50 \mathrm{~nm}$ thick silicon nitride window. Since the $\mathrm{Pu}$ ions lose only $300-400 \mathrm{keV}$ in this window, the resolution of the detector is substantially better than a silicon detector, and is sufficient to resolve the $3^{+} \mathrm{Pu}$ ions from $2^{+}$and $1^{+}$ions with the same $M / q$, as shown in Fig. 3. It appears that this system may even be suitable for high-sensitivity ${ }^{236} \mathrm{U}$ measurements (Wacker et al., 2005).

Perhaps paradoxically, this small system has the highest transmission of any AMS system for actinides. Stripping yield to the $3^{+}$charge state is surprisingly high at $20 \%$ and this, combined with minimal losses after stripping allow the Zurich system to achieve transmission as high as $15 \%$ from ion source to detector. By contrast, the corresponding figure for systems using the $5^{+}$charge state is $\sim 3 \%$.

\subsection{Weizmann Institute, Israel}

Techniques for analyzing both ${ }^{236} \mathrm{U}$ and plutonium isotopes have been developed by Paul et al. at the 14UD accelerator of the Weizmann Institute (Berkovits et al., 2000; Paul et al., 2001, 2003). Foil stripping to the $9^{+}$or $11^{+}$charge states at a terminal voltage of $7.1 \mathrm{MV}$ was employed. Transmission of $0.1-0.2 \%$ is significantly less than at facilities where gas stripping is used. The detection system provides both TOF and energy information for each ion.

\subsection{New facilities}

New AMS facilities based on 3 and 1 MV tandems have recently been installed in Naples and Seville, respectively. In both cases, the injection and analyzing magnets have been specified with future actinide measurements in mind.

\section{Efficiency}

Efficiency is the product of negative ion yield and transmission. Negative ion yield has been measured to be $0.3 \%$ for uranium by monitoring the current of ${ }^{238} \mathrm{U}^{16} \mathrm{O}^{-}$ ions from a sample containing a known amount of uranium as it was run to exhaustion (Fifield et al., 1996). Relative yields for $\mathrm{Th}, \mathrm{U}, \mathrm{Np}$ and $\mathrm{Pu}$ are listed in Table 2 and were determined using samples containing these elements in known proportions (Fifield et al., 1997).

Transmission from ion source to detector varies from system to system. At ANU, transmission in the $5^{+}$charge state is $\sim 3 \%$. From Table 2, the overall efficiency for detecting a plutonium ion is therefore $\sim 2 \times 10^{-4}$. Since backgrounds are very low, a signal of 10 counts is readily observable. Hence, sensitivities of $\sim 10^{5}$ atoms of ${ }^{236} \mathrm{U}$, ${ }^{237} \mathrm{~Np}$ or $\mathrm{Pu}$ are achievable with AMS.

\section{Backgrounds}

\subsection{Plutonium}

Although AMS of plutonium has intrinsically very low background levels, ions other than those of interest are also detected. The discussion below focuses on larger systems with accelerating voltages $\geqslant 3 \mathrm{MV}$ and detection of the $5^{+}$ charge state, but the concepts apply equally to other charge states. Smaller systems operating at $<1 \mathrm{MV}$ have their own issues, and these are introduced where appropriate. Background ions fall into two categories:

1. Other $5^{+}$ions with very similar energies. Of these, the most serious is ${ }^{238} \mathrm{U}$. After selection by the analyzing magnet, ${ }^{238} \mathrm{U}^{5+}$ and ${ }^{239} \mathrm{Pu}^{5+}$ differ in energy by only $0.4 \%$. This is well below the resolution of the ionization detector, which is invariably $>2 \%$. Those laboratories with a high-resolution ESA may be able to prevent the ${ }^{238} \mathrm{U}$ ions from reaching the detector, but a Wien filter

Table 2

Relative negative-ion formation probabilities for oxide ions of the actinides, normalized to $\mathrm{Pu}$

\begin{tabular}{ll}
\hline Negative ion & Relative formation probability \\
\hline $\mathrm{ThO}^{-}$ & $0.15 \pm 0.01$ \\
$\mathrm{UO}^{-}$ & $0.43 \pm 0.04$ \\
$\mathrm{NpO}^{-}$ & $0.77 \pm 0.02$ \\
$\mathrm{PuO}^{-}$ & 1.00 \\
\hline
\end{tabular}

${ }^{a}$ Absolute negative ion yields can be derived from this table using the observation that the yield for uranium oxide is $0.3 \%$. 
will not in general deflect the ${ }^{238} \mathrm{U}^{5+}$ ions sufficiently to allow the interception of all of the ${ }^{238} \mathrm{U}$ ions before the detector. Hence, it is important to understand the origin of the ${ }^{238} \mathrm{U}$ ions and the likely extent of the problem.

Uranium-containing negative molecular ions of mass 255, of which the most important is ${ }^{238} \mathrm{U}^{17} \mathrm{O}^{-}$, are injected into the accelerator along with the ${ }^{239} \mathrm{Pu}^{16} \mathrm{O}^{-}$ ions. Similarly, ${ }^{238} \mathrm{U}^{18} \mathrm{O}^{-}$ions are injected with ${ }^{240} \mathrm{Pu}^{16} \mathrm{O}^{-}$. After molecular dissociation and stripping in the high-voltage terminal and subsequent acceleration, ${ }^{238} \mathrm{U}^{5+}$ and ${ }^{239} \mathrm{Pu}^{5+}$ ions differ in momentum by $0.25 \%$. These particular ${ }^{238} \mathrm{U}^{5+}$ ions are not a problem because they are readily eliminated by the analyzing magnet, which is typically operated at a resolution of $0.1 \%$ or better in momentum.

The problematic ${ }^{238} \mathrm{U}^{5+}$ ions are rather those that have the same momentum as the ${ }^{239} \mathrm{Pu}^{5+}$ ions and that therefore pass around the analyzing magnet. To satisfy this condition, the ${ }^{238} \mathrm{U}^{5+}$ must gain an extra $0.4 \%$ of energy. Some of the ions that are stripped to $6^{+}$in the terminal can undergo charge-changing collisions and change to $5^{+}$. If these collisions occur $\sim 3 \%$ of the way down the high-energy tube, the ${ }^{238} \mathrm{U}$ ions will have the correct energy to pass around the analyzing magnet. The probability of this process is critically dependent on the vacuum in the high-energy tube - the better the vacuum, the lower the probability. Since gas-stripping is employed, a recirculating gas stripper with additional differential pumping to minimize the gas entering the high-energy tube is crucial.

Child et al. (2005) have explored this ${ }^{238} \mathrm{U}$ background as a function of the amount of uranium added to a blank sample, and found that even $1 \mathrm{ng}$ of uranium (i.e. about $1 \mathrm{ppm}$ in a $1 \mathrm{mg}$ sample) leads to an apparent ${ }^{239} \mathrm{Pu}$ signal of $10 \mathrm{fg}$. A sample to which no uranium was added yielded an apparent ${ }^{239} \mathrm{Pu}$ signal of $\sim 3 \mathrm{fg}$ due to residual uranium in the ion source or intrinsic to the sample. Their results are shown in Fig. 8. A similar (unpublished) study performed at the ANU showed a sensitivity to uranium concentration that was 2 orders of magnitude lower than reported by Child et al., i.e. $100 \mathrm{ng}$ of uranium was required to produce an apparent ${ }^{239} \mathrm{Pu}$ signal of $10 \mathrm{fg}$. This has subsequently been borne out by regular measurements at the ANU on process blanks which routinely exhibit an apparent ${ }^{239} \mathrm{Pu}$ signal of $<0.2 \mathrm{fg}$. This lower sensitivity to uranium highlights the importance of the vacuum in the high-energy acceleration tube close to the high-voltage terminal. In the ANU's 14UD accelerator, this is typically better than $10^{-8}$ Torr due to the excellent pumping of the gas stripper and the intrinsically high vacuum of the NEC tube design.

Uranium backgrounds at ${ }^{240} \mathrm{Pu}$ can be higher than at ${ }^{239} \mathrm{Pu}$ because the ${ }^{238} \mathrm{U}^{18} \mathrm{O}^{-}$ion is five times more prolific than the ${ }^{238} \mathrm{U}^{17} \mathrm{O}^{-}$ion. If these oxide molecules, rather than the ${ }^{238} \mathrm{U}^{16} \mathrm{OH}^{-}$ion or the high-energy tail of the ${ }^{238} \mathrm{U}^{16} \mathrm{O}^{-}$ion distribution, are the principal source

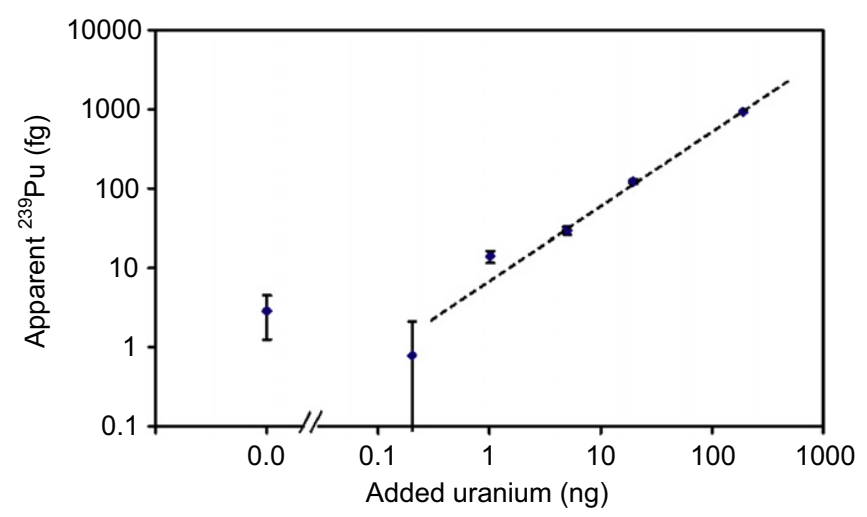

Fig. 8. Apparent $\mathrm{Pu}$ in fg due to background ${ }^{238} \mathrm{U}$ ions that are indistinguishable from ${ }^{239} \mathrm{Pu}$ ions in the detector, as a function of uranium concentration in the sample. Reprinted with permission from Child et al. (2005).

of ${ }^{238} \mathrm{U}$ ions in the accelerator, then the ${ }^{238} \mathrm{U}$ background at ${ }^{240} \mathrm{Pu}$ will be approximately five times higher than at ${ }^{239} \mathrm{Pu}$. There is some evidence that this is the case, at least for the ANU system (Fifield et al., 1996).

2. The second category of non-Pu ions that may arrive at the detector is ions with lower charge states but approximately the same $M / q$. To consider a specific example, any ${ }^{191} \mathrm{Pt}^{4+}$ ions with the same $M E / q^{2}$ as ${ }^{239} \mathrm{Pu}^{5+}$ ions will be only slightly deflected by a Wien filter (or will pass around an ESA) and will therefore reach the ionization detector when the AMS system is set to transmit ${ }^{239} \mathrm{Pu}$. Because they have only $4 / 5$ of the energy of the ${ }^{239} \mathrm{Pu}$ ions, they are readily distinguished by the ionization chamber, and hence are only a problem if counting rates are high. They have their origin in injection of molecular negative ions of mass 255. Possibilities involving common elements would be ${ }^{191} \mathrm{Pt}^{16} \mathrm{O}_{4},{ }^{191} \mathrm{Pt}^{48} \mathrm{Ti}^{16} \mathrm{O}$, or ${ }^{191} \mathrm{Pt}^{32} \mathrm{~S}^{16} \mathrm{O}_{2}$. Because $M / q$ for ${ }^{191} \mathrm{Pt}^{4+}$ ions is not exactly the same as for ${ }^{239} \mathrm{Pu}^{5+}$ ions, a charge-changing collision from $5^{+}$to $4^{+}$in the high-energy tube is necessary to give the ${ }^{191} \mathrm{Pt}$ the correct energy to traverse the analyzing magnet. Taken together, the low natural abundance of platinum, the complexity of the molecules, and the low probability of the charge-changing collision result in extremely low counting rates of ${ }^{191} \mathrm{Pt}^{4+}$ ions at the detector. This is equally true of the lower charge state ions ${ }^{143} \mathrm{Sm}^{3+}$, ${ }^{96} \mathrm{Mo}^{2+}$ and ${ }^{48} \mathrm{Ti}^{+}$, as can be seen in Fig. 2a. Similar considerations apply to ${ }^{242} \mathrm{Pu}$, for which a typical spectrum is shown in Fig. 2c. Clearly, if a charge state different from $5^{+}$is employed, different background ions with different energies come into play. For example, if $3^{+}$ions are selected, as is generally the case for the smaller systems, then the background ions are ${ }^{159} \mathrm{~Tb}^{2+}$ and ${ }^{80} \mathrm{Se}^{+}$. Further, in the cases of the smaller systems, energy straggling in the stripper may remove the need for a charge-changing collision so that, for example, some ${ }^{159} \mathrm{~Tb}^{2+}$ ions directly from the stripper may have the correct energy to pass the analyzing 
magnet. This situation is then closely analagous to the ${ }^{240} \mathrm{Pu}$ case described below.

The situation is, however, rather different for ${ }^{240} \mathrm{Pu}^{5+}$. In this case, $M / q$ is an integer. Ignoring differences in binding energies for the moment, it follows that there is no need to invoke a chargechanging collision in the high-energy tube. Atoms stripped to ${ }^{48} \mathrm{Ti}^{+},{ }^{96} \mathrm{Mo}^{2+},{ }^{144} \mathrm{Sm}^{3+}$, and ${ }^{192} \mathrm{Pt}^{4+}$ in the gas stripper will have the correct energy after the second stage of acceleration to pass around the analyzing magnet. Hence, counting rates of these ions can be orders of magnitude higher at the ${ }^{240} \mathrm{Pu}$ settings than at ${ }^{239} \mathrm{Pu}$ or ${ }^{242} \mathrm{Pu}$ settings, as illustrated by Fig. $2 \mathrm{~b}$. Nevertheless, counting rates are generally well within the capabilities of the detector. Note, however, that ${ }^{240} \mathrm{Pu}$ is rather less tightly bound than the lighter interferences, i.e. $M / A$ for ${ }^{240} \mathrm{Pu}$ is $0.12 \%$ greater than ${ }^{96} \mathrm{Mo}$ for example. As a result, ${ }^{240} \mathrm{Pu}^{5+}$ and ${ }^{96} \mathrm{Mo}^{2+}$ do not follow exactly the same average trajectories in the analyzing magnet. With appropriate apertures, the counting rates of the $M / q$ interferences can be reduced substantially, especially when the analyzing magnet is followed by a high-resolution ESA.

\section{Uranium-236}

AMS of ${ }^{236} \mathrm{U}$ must contend with the fact that uranium is a major constituent of the sample. Backgrounds from ${ }^{238} \mathrm{U}$ and ${ }^{235} \mathrm{U}$, which arise in essentially the same way as the ${ }^{238} \mathrm{U}$ background in the plutonium case described above, will therefore be a more serious problem than was the case for plutonium.

At the ${ }^{236} \mathrm{U}$ settings, the mass- $252{ }^{236} \mathrm{U}^{16} \mathrm{O}^{-}$ion is selected for injection into the accelerator. Other ions of the same mass, but with either ${ }^{238} \mathrm{U}$ or ${ }^{235} \mathrm{U}$ as a constituent, are ${ }^{238} \mathrm{U}^{14} \mathrm{~N}^{-},{ }^{238} \mathrm{U}^{12} \mathrm{CH}_{2}^{-},{ }^{235} \mathrm{U}^{17} \mathrm{O}^{-}$, and ${ }^{235} \mathrm{U}^{16} \mathrm{OH}^{-}$. Of these, ${ }^{235} \mathrm{U}^{17} \mathrm{O}^{-}$is unavoidable and will be injected with a beam current of $\sim 0.3 \mathrm{pA}\left(\sim 2 \times 10^{6}\right.$ ions/s $)$ when the ${ }^{238} \mathrm{U}^{16} \mathrm{O}^{-}$output is $100 \mathrm{nA}$. Experience with plutonium suggests that the $\mathrm{U}^{16} \mathrm{OH}^{-}$beam is generally weaker than the $\mathrm{U}^{17} \mathrm{O}^{-}$beam.

Measurements on test samples at the ANU showed that, although the ${ }^{238} \mathrm{U}^{14} \mathrm{~N}^{-}$ion can be a significant source of background if the sample is in the form of uranium nitrate, the normal procedure of baking the samples at $800^{\circ} \mathrm{C}$ is very effective at eliminating nitrogen. Hence the ${ }^{238} \mathrm{U}^{14} \mathrm{~N}^{-}$ ion does not contribute materially to the ${ }^{238} \mathrm{U}$ background for "real" samples.

Further, the addition of $1 \mathrm{mg}$ of graphite to a uranium oxide sample did not increase the ${ }^{238} \mathrm{U}$ background, which implies that the ${ }^{238} \mathrm{U}^{12} \mathrm{CH}_{2}^{-}$ion is not an important source of background either.

In fact, the principal source of background appears to arise from the low-energy tail of the ${ }^{238} \mathrm{U}^{16} \mathrm{O}^{-}$beam. Specifically, if a ${ }^{238} \mathrm{U}^{16} \mathrm{O}^{-}$ion has $0.8 \%$ less energy than normal, it will be accepted by the injector magnet and injected into the accelerator. The most likely mechanism for producing such lower-energy ions is the formation of "hot" molecules which break up during the extraction process in the ion source (Litherland, 1987). Similarly, ${ }^{235} \mathrm{U}^{16} \mathrm{O}^{-}$ions with $0.4 \%$ more energy than normal will also be accepted. Some ions can gain extra energy from backscattered Cs ions during the sputtering process. A detailed discussion of the various mechanisms is given by Litherland (1987) in the context of carbon beams. Although the relative contributions of the different sources of background are difficult to quantify, it is believed that these energy-degraded ${ }^{238} \mathrm{U}^{16} \mathrm{O}^{-}$ions are the dominant source of background in the ANU system.

Some AMS systems have an energy-analysing ESA between the ion source and the injector magnet. Provided that this has sufficiently high resolution, the energy-degraded ${ }^{238} \mathrm{U}^{16} \mathrm{O}^{-}$or energy-enhanced ${ }^{235} \mathrm{U}^{16} \mathrm{O}^{-}$ions can be eliminated before the injector magnet. A resolution $E / \Delta E>250$ would be required to eliminate both.

\section{Sample preparation}

\subsection{Plutonium}

Sample preparation methods have been adapted from techniques developed for $\alpha$-particle counting. There are three stages:

(i) Initial scavenging of the plutonium from the original sample. If a ${ }^{242} \mathrm{Pu}$ spike is required, it is added at this stage. Four possibilities can be distinguished:

(a) Soils and sediments: The plutonium will generally reside on the surfaces of the grains, and hence can be liberated by leaching in hot $8 \mathrm{M}$ nitric acid (Tims et al., 2004). An exception is the case of "hot" particles in soil from a nuclear accident for example, which will not in general be completely leached and are better treated as in (d).

(b) Water, including ice: Plutonium is co-precipitated with either $\mathrm{Fe}(\mathrm{OH})_{3}$ or $\mathrm{MnO}_{2}$ by adding a suitable amount of $\mathrm{Fe}$ or $\mathrm{Mn}$ and then making the solution alkaline with $\mathrm{NaOH}$.

(c) Biological samples, e.g. blood, feces or urine: The $\mathrm{Pu}$ is generally co-precipitated with either calcium phosphate or calcium/magnesium phosphate.

(d) Rocks, and in particular uranium ores (for measurement of Pu produced in situ by neutron absorption by $\left.{ }^{238} \mathrm{U}\right)$. After crushing and sieving, the $<250 \mu \mathrm{m}$ fraction is dissolved in a 40:60 mixture of concentrated $\mathrm{HF}$ and $\mathrm{HNO}_{3}$. This effectively dissolves any uranium-bearing minerals, including silicates. Often, a residue of graphite and sulfides remains after dissolution, but these contain very little of the uranium, or by implication, of the plutonium. Insoluble fluorides are also precipi- 
tated. Since $\mathrm{PuF}_{4}$ is insoluble, it is necessary to take the fluorides back into solution with $\mathrm{HNO}_{3}$ and to drive off the fluorine as HF by repeatedly drying down from nitric acid solution.

(ii) Separation of the actinides from everything else. This step is often omitted when uranium levels are low, but is essential for uranium ores. After taking the scavenged sample back into solution, this separation is usually accomplished with U-TEVA ${ }^{\mathrm{TM}}$ (uranium tetravalent) ion-exchange resin (Eichrom Industries, Chicago). The sample is loaded on to the column in $3 \mathrm{M}$ nitric acid, and only uranium and other tetravalent actinides are retained on the column as nitrato-complexes. Plutonium and thorium can then be selectively eluted by a mixture of $5 \mathrm{M}$ hydrochloric and $0.05 \mathrm{M}$ oxalic acids. Uranium is subsequently eluted with dilute $0.01 \mathrm{M}$ hydrochloric acid.

(iii) Plutonium may be separated from any residual uranium, and less importantly from thorium and other actinides, on an anion-exchange column, Bio-Rad AG $1-\mathrm{X} 8$, for example. The plutonium is loaded on to the column in $8 \mathrm{M}$ nitric acid and any residual uranium washed through with additional acid. Thorium can then be eluted with $12 \mathrm{M}$ hydrochloric acid. Finally, plutonium is eluted from the resin with a freshly made, warm $\left(40^{\circ} \mathrm{C}\right)$ mixture of $12 \mathrm{M} \mathrm{HCl}$ and $0.1 \mathrm{M} \mathrm{NH}_{4} \mathrm{I}$. The iodide ion reduces $\mathrm{Pu}$ to its trivalent state, breaking the anionic complex and releasing the $\mathrm{Pu}$ from the column.

At the end of this procedure, the plutonium and very little else is in solution. In order to produce a sample for the ion source, considerably more bulk than would be provided by a few pg of $\mathrm{Pu}$ is, however, required. Almost invariably, this has been provided by iron oxide. Typically, $1-2 \mathrm{mg}$ of iron as $\mathrm{Fe}\left(\mathrm{NO}_{3}\right)_{3}$ is added to the plutonium-containing solution. The solution is then either simply evaporated to dryness, or iron is precipitated as $\mathrm{Fe}(\mathrm{OH})_{3}$ by making the solution alkaline. The resulting solid is converted to $\mathrm{Fe}_{2} \mathrm{O}_{3}$ by baking at $800^{\circ} \mathrm{C}$, mixed with a conductor that has variously been aluminum, silver, copper or niobium, and pressed into a sample holder.

\subsection{Uranium}

In contrast to plutonium, where efficiency is paramount and where it is important to ensure valence equilibrium between the ${ }^{242} \mathrm{Pu}$ spike and $\mathrm{Pu}$ in the sample, the chemistry for extracting uranium is more forgiving in the sense that the principal requirement is only that enough uranium be extracted for a measurement, Since no spike is added, efficiency of extraction and equilibration are not serious issues.

\section{Applications}

\subsection{Tracing discharges from plutonium-processing and fuel reprocessing plants}

In a series of papers, Oughton and co-workers have employed AMS to measure plutonium concentrations and plutonium and uranium isotopic ratios in regions affected by the nuclear-weapons production complex of the former Soviet Union. Specifically

1. In the vicinity of the Mayak production and processing facility in the Urals, significant releases of plutonium have contaminated the local environment. In the 1950s, waste containing weapons grade plutonium with low ${ }^{240} \mathrm{Pu} /{ }^{239} \mathrm{Pu}$ ratios $(<5 \%)$ was released directly to the Techa River. The Techa is a tributary of the $\mathrm{Ob}$ river which is one of the two major rivers draining Siberia to the Arctic Ocean. Subsequently, containment dams were built to intercept waste, and the plant reprocessed an increasing proportion of waste from civil nuclear power reactors. Hence ${ }^{240} \mathrm{Pu} /{ }^{239} \mathrm{Pu}$ and ${ }^{236} \mathrm{U} /{ }^{238} \mathrm{U}$ ratios change over time. In addition, an explosion in a high-level waste tank in 1963 sent a plume of radioactive material to the northeast of the plant. Plutonium measurements have been carried out in the swamp just downstream of the containment dams, which would have received some of the earliest releases, in water and sediments from the dams themselves, in soils and sediments down the Techa River and from areas affected by the Khyshtym accident, and in present-day water from the river (Borretzen et al., 2005; Oughton et al., 2000). In addition, ${ }^{236} \mathrm{U} /{ }^{238} \mathrm{U}$ ratios have been measured in both the swamp and the dams (Borretzen et al., 2005). Taken together, these give a rather complete picture of the quantities and origins of plutonium in the environs of the plant, and the extent to which it has dispersed. In particular, plutonium from the plant's operations is barely detectable in the river at distances greater than $200 \mathrm{~km}$ from the plant.

2. In contrast, measurements in sediments and water from the other major Siberian river, the Yenisey, point to an influence of the Krasnoyarsk processing plant. Located $1000 \mathrm{~km}$ upstream from the estuary, its influence is evidenced by low ${ }^{240} \mathrm{Pu} /{ }^{239} \mathrm{Pu}$ ratios in both water and sediment from the upper reaches of the estuary (Lind et al., 2006; Skipperud et al., 2004). This influence extends out into the Kara Sea, and back into the adjacent estuary of the $\mathrm{Ob}$.

3. Nuclear reactors from decommissioned submarines and other nuclear waste has been dumped near Novaya Zemlya in the Russian Arctic. Ratios of ${ }^{240} \mathrm{Pu} /{ }^{239} \mathrm{Pu}$ have been employed to monitor possible leakage from these dumping sites (Oughton et al., 2004).

AMS has also been employed to study the dispersal of ${ }^{237} \mathrm{~Np}$ and ${ }^{236} \mathrm{U}$ discharged from the Sellafield reprocessing 
plant in Cumbria, UK. Keith-Roach et al. (2000) measured the seasonal variation of ${ }^{237} \mathrm{~Np}$ in pore water in a nearby salt marsh, and compared it with $\mathrm{Pu}$ and ${ }^{241} \mathrm{Am}$ in order to investigate the influence of microbial activity in mobilizing these isotopes. Marsden et al. (2006, 2001) measured ${ }^{236} \mathrm{U} /{ }^{238} \mathrm{U}$ ratios as a function of depth in sediments from the same marsh to complement radiometric measurements of concentrations of $\mathrm{Pu}$ isotopes, ${ }^{241} \mathrm{Am}$ and ${ }^{244} \mathrm{Cm}$. Comparison with the documented history of releases from the Sellafield plant yields important information on the mechanisms that disperse the discharges into the environment.

\subsection{Human biochemistry of plutonium}

A major benefit of the high sensitivity of AMS is that it allows biomedical studies on human subjects because doses of long-lived radionuclides can be kept very low. This is particularly important in the case of plutonium, since its isotopes are $\alpha$-particle emitters and the element is chemically toxic. Nature has been kind in that the longest-lived plutonium isotope, ${ }^{244} \mathrm{Pu}$, has a half-life of $80 \mathrm{Ma}$ and hence a very low specific activity. Further, although it can be extracted from spent reactor fuel, it was produced in only negligible quantities by nuclear weapons testing. Hence, the combination of low specific activity and absence from the natural environment make it a useful tracer of plutonium uptake, retention and excretion in human subjects. Two studies in which AMS has been used to detect the ${ }^{244} \mathrm{Pu}$ in blood, urine and fecal samples have been reported (Etherington et al., 2003; Newton et al., 2005; Stradling et al., 2002).

In the first (Newton et al., 2005), a group of six women were given a dose of mixed ${ }^{237} \mathrm{Pu}$ and ${ }^{244} \mathrm{Pu}$ by intravenous injection in 1995 . It was necessary to purify the ${ }^{244} \mathrm{Pu}$ by mass-separation so that only traces of the other plutonium isotopes remained, in order to minimize the radiological burden to the subjects. The ${ }^{237} \mathrm{Pu}$, with its half-life of 37 days, allowed the short-term behavior of the dose to be followed by $\gamma$-ray counting. Subsequently, it has been possible to follow the decline in plutonium in the subjects out to 8 years by measuring ${ }^{244} \mathrm{Pu}$ in blood and urine samples by AMS. Even after 8 years, ${ }^{244} \mathrm{Pu}$ is still detectable in a $20 \mathrm{ml}$ blood sample.

The second study determined the uptake of plutonium from the lungs when the plutonium was attached to aerosols (Etherington et al., 2003; Stradling et al., 2002). This was designed to mimic the most probable pathway for uptake by workers in nuclear processing plants.

\subsection{Safeguards}

A potential application of AMS in the nuclear safeguards area is the identification of clandestine nuclear activities by measuring ${ }^{236} \mathrm{U}$ in small particles. These may have been collected as aerosols or from the leaves of plants, and elevated ${ }^{236} \mathrm{U} /{ }^{238} \mathrm{U}$ ratios would constitute unambig- uous evidence of material that had passed through a nuclear reactor (Hotchkis et al., 2000a, b).

A closely related application is the identification of areas contaminated by depleted uranium weaponry. Armourpiercing shells made of depleted uranium were used in the recent Iraq and Kosovo wars, and there are concerns about possible health effects on both military personnel and the civilian population of the affected areas. Depleted uranium is a by-product of the uranium-enrichment process, and the feedstock often contains some recycled reactor fuel with high levels of ${ }^{236} \mathrm{U}$. Hence, some ${ }^{236} \mathrm{U}$ finds its way into the depleted uranium and can serve as a very sensitive fingerprint of the presence of depleted uranium in an area (Danesi et al., 2003). Again, the high sensitivity of AMS is required for its detection.

AMS has also been applied to the measurement of ${ }^{240} \mathrm{Pu} /{ }^{239} \mathrm{Pu}$ ratios in soil samples from the Palomares region of Spain (Chamizo et al., 2006) where, in 1966, a B52 bomber accident released the fuel from two thermonuclear weapons. This ratio is the most sensitive indicator of small traces of the weapons-grade material from the accident, allowing it to be distinguished from global fallout.

\subsection{Plutonium as a tracer of soil erosion and sediment transport}

Plutonium has advantages in terms of sample size, sensitivity and precision over the widely used ${ }^{137} \mathrm{Cs}$ as a tracer of soil erosion and sediment transport over the past 50 years. Both were produced by nuclear weapons testing in the 1950s and 1960s, and subsequently dispersed globally. Both bind tightly to soil and sediment particles, especially in terrestrial environments, and hence may be used to track the erosion of soil particles and their subsequent transport by river systems to the sea.

Approximately five times as many atoms of $\mathrm{Pu}$ as of ${ }^{137} \mathrm{Cs}$ were produced. Decay of ${ }^{137} \mathrm{Cs}$ in the intervening $\sim 45$ years has increased this ratio to $\sim 14$. Whereas ${ }^{137} \mathrm{Cs}$ is readily detected via its characterisitic $662 \mathrm{keV} \gamma$-ray, AMS is the method of choice for the detection of $\mathrm{Pu}$ in sediments, although some work has been done with $\alpha$ particle counting. Sample sizes for AMS are typically $4 \mathrm{~g}$ of soil or sediment, and the same number of counts can be achieved for ${ }^{239} \mathrm{Pu}$ in $7 \mathrm{~min}$ of counting as is achieved for ${ }^{137} \mathrm{Cs}$ in 2 days of counting of a $100 \mathrm{~g}$ sample. Further, since the ${ }^{137} \mathrm{Cs} \gamma$-ray peak sits on a background which must be subtracted, the statistical precision of the essentially background-free $\mathrm{Pu}$ measurements is higher. AMS counting times of $\sim 1 \mathrm{~h}$ are quite feasible, which allows even higher precision to be achieved if desired. Sample preparation is somewhat more complex for $\mathrm{Pu}$ than for ${ }^{137} \mathrm{Cs}$, but is not especially difficult.

A pilot study is underway in the $10,000 \mathrm{~km}^{2}$ Herbert River catchment in NE Queensland, Australia to determine the relative merits of $\mathrm{Pu}$ and ${ }^{137} \mathrm{Cs}$. This catchment covers 


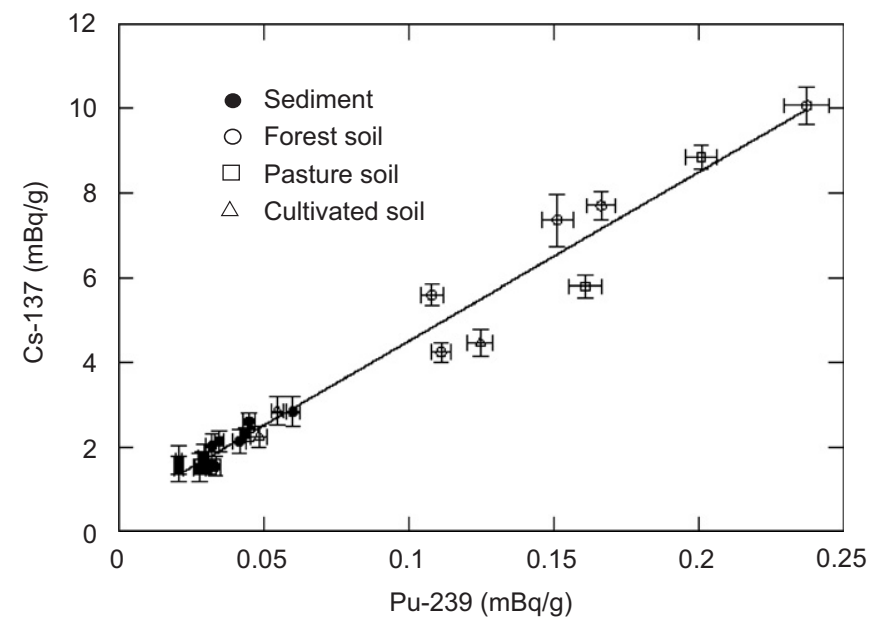

Fig. 9. Plot of ${ }^{137} \mathrm{Cs}$ concentration vs ${ }^{239} \mathrm{Pu}$ concentration for terrestrial samples from a range of land-use areas in the Herbert River catchment, N. Qld, Australia. From Everett et al. (2007).

grazing land in its upper reaches, undisturbed forest in the middle reaches, and intensive sugarcane agriculture on the coastal plains. Soils and sediments collected from each of these land-use types show a very good correlation between $\mathrm{Pu}$ and ${ }^{137} \mathrm{Cs}$ as shown in Fig. 9.

\subsection{Ores}

Although ${ }^{239} \mathrm{Pu}$ and ${ }^{236} \mathrm{U}$ are generally thought of as exclusively man-made isotopes, they do in fact occur naturally in uranium ores, albeit at very low levels. Indeed, Seborg first reported the detection of natural plutonium in an ore from Cigar Lake in Saskatchewan as early as 1948. The processes that produce these isotopes are the same as in a reactor, i.e. neutron capture by ${ }^{238} \mathrm{U}$ and ${ }^{235} \mathrm{U}$, respectively. The neutrons are generated principally by spontaneous fission of ${ }^{238} \mathrm{U}$ and by $(\alpha, \mathrm{n})$ reactions on light elements such as $\mathrm{Na}, \mathrm{Mg}$ and $\mathrm{Al}$. In a typical ore-bearing rock, these two contributions are approximately equal.

Potential applications include neutron flux monitoring (Purser et al., 1996), fingerprinting individual ores, and exploration for new uranium deposits.

Neutron fluxes in an ore body are determined not only by the uranium content, but also by the water content, the concentrations of major neutron-producing elements such as $\mathrm{Na}, \mathrm{Mg}$ and $\mathrm{Al}$, and by the concentrations of trace neutron absorbers such as B, Gd and $\mathrm{Sm}$. Since ${ }^{239} \mathrm{Pu}$ is produced by absorption of epithermal neutrons, whereas ${ }^{236} \mathrm{U}$ is produced largely by capture of thermal neutrons, it is possible to deduce both the thermal and epithermal neutron fluxes in the ore over the past $50 \mathrm{ka}$ from measurements of both isotopes.

A particular concern of uranium-producing countries is that their uranium might find its way into nuclear weapons. Hence a fingerprint of a particular ore-body, or even of a particular shipment of ore, would allow that specific uranium to be tracked. Any processing of the ore is not going to change the uranium isotopic composition, and hence the ${ }^{236} \mathrm{U} /{ }^{238} \mathrm{U}$ ratio might serve as such a fingerprint.

The presence of detectable amounts of ${ }^{236} \mathrm{U}$ in highuranium groundwater would be a strong indicator that the uranium was derived from an ore-body. Hence, the ${ }^{236} \mathrm{U} /{ }^{238} \mathrm{U}$ ratio may prove to be a useful exploration tool in the search for new uranium deposits.

\section{Summary}

Accelerator mass spectrometry is proving to be an exquisitely sensitive tool for studying long-lived actinides in the environment, and an increasing number of AMS laboratories are adding an actinide capability to their repertoire. Applications range across a broad spectrum. Isotopes of plutonium are finding application in tracing the dispersal of releases from nuclear accidents and reprocessing operations, in studies of the biokinetics of the element in humans, and as a tracer of soil loss and sediment transport. Uranium-236 has also been used to track nuclear releases, but additionally has a role to play in nuclear safeguards and in determining the extent of environmental contamination in modern theaters of war due to the use of depleted uranium weaponry.

\section{Editorial handling by: R. Grun}

\section{References}

Berkovits, D., Feldstein, H., Ghelberg, S., Hershkowitz, A., Navon, E., Paul, M., 2000. ${ }^{236} \mathrm{U}$ in uranium minerals and standards. Nuclear Instruments and Methods B 172, 372-376.

Borretzen, P., Standring, W.J.F., Oughton, D.H., Dowdall, M., Fifield, L.K., 2005. Plutonium and uranium atom ratios and concentration factors in Reservoir 11 and Asanov Swamp, Mayak PA: an application of accelerator mass spectrometry. Environmental Science and Technology 39, 92-97.

Brown, T.A., Marchetti, A.A., Martinelli, R.E., Cox, C.C., Knezovich, J.P., Hamilton, T.F., 2004. Actinide measurements by accelerator mass spectrometry at Lawrence Livermore National Laboratory. Nuclear Instruments and Methods B 223-224, 788-795.

Chamizo, E., Garcia-Leon, M., Synal, H.-A., Suter, M., Wacker, L., 2006. Determination of the ${ }^{240} \mathrm{Pu} /{ }^{239} \mathrm{Pu}$ atomic ratio in soils from Palomares (Spain) by low-energy accelerator mass spectrometry. Nuclear Instruments and Methods B 249, 768-771.

Child, D.P., Hotchkis, M.A.C., Williams, M.L., 2005. Improvements in actinide and fission product analysis by AMS-raising the bar and lowering detection limits in heavy element AMS. In: Proceedings of the 46th Annual Meeting of the Institute for Nuclear Materials Management, July 10-14, 2005, AZ, USA.

Danesi, P.R., Bleise, A., Burkart, W., Cabianca, T., Campbell, M.J., Makarewicz, M., Moreno, J., Tuniz, C., Hotchkis, M., 2003. Isotopic composition and origin of uranium and plutonium in selected soil samples collected in Kosovo. Journal of Environmental Radioactivity 64, 121-131.

Desideri, D., Meli, M.A., Roselli, C., Testa, C., Boulyga, S.F., Becker, J.S., 2002. Determination of ${ }^{236} U$ and transuranium elements in depleted uranium ammunition by $\alpha$-spectrometry and ICP-MS Analytical and Bioanalytical Chemistry 374, 1091-1095. 
Etherington, G., Stradling, G.N., Hodgson, A., Fifield, L.K., 2003. Anomalously high excretion of $\mathrm{Pu}$ in urine following inhalation of plutonium nitrate. Radiation Protection Dosimetry 105, 321-324.

Everett, S.J., Tims, S.G., Hancock, G.J., Fifield, L.K., 2007. Comparison of $\mathrm{Pu}$ and ${ }^{137} \mathrm{Cs}$ as tracers of sediment transport in terrestrial environments. Journal of Environmental Radioactivity, in press.

Fifield, L.K., Cresswell, R.G., Tada, M.L.D., Ophel, T.R., Day, J.P., Clacher, A.P., King, S.J., Priest, N.D., 1996. Accelerator mass spectrometry of plutonium isotopes. Nuclear Instruments and Methods B 117, 295-303.

Fifield, L.K., Clacher, A.P., Morris, K., King, S.J., Cresswell, R.G., Day, J.P., Livens, F.R., 1997. Accelerator mass spectrometry of the planetary elements. Nuclear Instruments and Methods B 123, 400-404.

Fifield, L.K., Synal, H.-A., Suter, M., 2004. Accelerator mass spectrometry of plutonium at $300 \mathrm{kV}$. Nuclear Instruments and Methods B 223-224, 802-806.

Hotchkis, M., Fink, D., Tuniz, C., Vogt, S., 2000a. Accelerator mass spectrometry analyses of environmental radionuclides: sensitivity, precision and standardisation. Applied Radiation and Isotopes 53 (1-2), 31-37.

Hotchkis, M.A.C., Child, D., Fink, D., Jacobsen, G.E., Lee, P.J., Mino, N., Smith, A.M., Tuniz, C., 2000b. Measurement of ${ }^{236} \mathrm{U}$ in environmental media. Nuclear Instruments and Methods B 172, 659-665.

Hrnecek, E., Steier, P., Wallner, A., 2005. Determination of plutonium in environmental samples by AMS and alpha spectrometry. Applied Radiation and Isotopes 63, 633-638.

Keith-Roach, M.J., Day, J.P., Fifield, L.K., Bryan, N.D., Livens, F.R., 2000. Seasonal variations in interstitial water transuranium concentrations. Environmental Science and Technology 34, 4273-4277.

Ketterer, M.E., Hafer, K.M., Link, C.L., Royden, C.S., Hartsock, W.J., 2003. Anthropogenic ${ }^{236} \mathrm{U}$ at rocky flats, Ashtabula river harbor, and Mersey estuary: three case studies by sector inductively coupled plasma mass spectrometry. Journal of Environmental Radioactivity 67, 191-206.

Liechtenstein, V.K., Ivkova, T.M., Olshanski, E.D., Golser, R., Kutschera, W., Steier, P., Vockenhuber, C., Repnow, R., Hahn, R.V., Friedrich, M., Kreissig, U., 2004. Recent investigations and applications of thin diamond-like carbon (DLC) foils. Nuclear Instruments and Methods A 521, 197-202.

Lind, O.C., Oughton, D.H., Salbu, B., Skipperud, L., Sickel, M.A., Brown, E., Fifield, L.K., Tims, S.G., 2006. Transport of low ${ }^{240} \mathrm{Pu} /{ }^{239} \mathrm{Pu}$ atom ratio plutonium-species in the $\mathrm{Ob}$ and Yenisey Rivers to the Kara Sea. Earth and Planetary Science Letters 251, 33-43.

Litherland, A.E., 1987. Fundamentals of accelerator mass spectrometry. Philosophical Transactions of the Royal Society of London A 323, 5-21.

Marsden, O.J., Livens, F.R., Day, J.P., Fifield, L.K., Goodal, P.S., 2001. Determination of U-236 in sediment samples by accelerator mass spectrometry. Analyst 126, 633-636.

Marsden, O.J., Abrahamsen, L., Bryan, N.D., Day, J.P., Fifield, L.K., Gent, C., Goodal, P.S., Morris, K., Livens, F.R., 2006. Transport and accumulation of actinide elements in the near-shore environment: field and modelling studies. Sedimentology 53, 237-248.

McAninch, J.E., Hamilton, T.F., Brown, T.A., Jokela, T.A., Knezovich, J.P., Ognibene, T.J., Proctor, I.D., Roberts, M.L., Sideras-Haddad, E., Southon, J.R., Vogel, J.S., 2000. Plutonium measurements by accelerator mass at LLNL. Nuclear Instruments and Methods B 172, 711-716.

Newton, D., Talbot, R.J., Pich, G.M., Fifield, L.K., Priest, N.D., 2005. Long-term behaviour of injected plutonium in healthy women. In: Oeh, U., Roth, P., Paretzke, H.G. (Eds.), Proceedings of 9th International Conference on Health Effects of Incorporated Radionuclides, Neuherberg, Germany, November 29 to Dec 1, 2004, pp. 311-317. Available from; 〈http://www.gsf.de/heir/ProceedingsHEIR2004_ebook.pdf $>$.

O’Donnell, R.G.G., Mitchell, P.I., Priest, N.D., Strange, L., Fox, A., Henshaw, D.L., Long, S.C., 1997. Variations in the concentration of plutonium, strontium-90 and total alpha-emitters in human teeth collected within the British Isles. Science of the Total Environment 201, 235-243.

Oughton, D.H., Fifield, L.K., Day, J.P., Cresswell, R.G., Skipperud, L., Di Tada, M.L., Salbu, B., Strand, P., Drozcho, E., Mokrov, Y., 2000. Plutonium from Mayak: measurement of isotope ratios and activities using accelerator mass spectrometry. Environmental Science and Technology 34, 1938-1945.

Oughton, D.H., Skipperud, L., Fifield, L.K., Cresswell, R.G., Salbu, B., Day, P., 2004. Accelerator mass spectrometry measurement of ${ }^{240} \mathrm{Pu} /{ }^{239} \mathrm{Pu}$ isotope ratios in Novaya Zemlya and Kara Sea sediments. Applied Radiation and Isotopes 61, 249-253.

Paul, M., Valenta, A., Ahmad, I., Berkovits, D., Bordeanu, C., Ghelberg, S., Hashimoto, Y., Hershkowitz, A., Jiang, S., Nakanishi, T., Sakamoto, K., 2001. Experimental limit to interstellar ${ }^{244} \mathrm{Pu}$ abundance. Astrophysical Journal 558, L133-L135.

Paul, M., Valenta, A., Ahmad, I., Berkovits, D., Bordeanu, C., Ghelberg, S., Hershkowitz, Y.H., Jiang, S., Nakanishi, T., Sakamoto, K., 2003. A window on nucleosynthesis through detection of short-lived radionuclides. Nuclear Physics A 719, C29-C39.

Purser, K.H., Kilius, L.R., Litherland, A.E., Zhao, X.-L., 1996. Detection of ${ }^{236} \mathrm{U}$ : a possible 100 -million year neutron flux integrator. Nuclear Instruments and Methods B 113, 445-452.

Richter, S., Alonso, A., Bolle, W.D., Wellum, R., Taylor, P.D.P., 1999. Isotopic "fingerprints" for natural uranium ore samples. International Journal of Mass Spectrometry 193, 9-14.

Skipperud, L., Oughton, D.H., Fifield, L.K., Lind, O.C., Tims, S., Brown, J., Sickel, M., 2004. Plutonium isotope ratios in the Yenisey and $\mathrm{Ob}$ estuaries. Applied Radiation and Isotopes 60, 589-593.

Starzecki, W., Stefanini, A.M., Lunardi, S., Signorini, C., 1982. A compact time-zero detector for mass identification of heavy ions. Nuclear Instruments and Methods 193, 499-505.

Steier, P., Golser, R., Kutschera, W., Liechtenstien, V., Priller, A., Valenta, A., Vockenhuber, C., 2002. Heavy ion AMS with a "small" accelerator. Nuclear Instruments and Methods B 188, 283-287.

Stradling, N., Etherington, G., Hodgson, A., Bailey, M.R., Hodgson, S., Pellow, P., Shutt, A.L., Birchall, A., Rance, E., Newton, D., Fifield, K., 2002. Comparison between biokinetics of inhaled plutonium nitrate and gadolinium oxide in humans and animals. Journal of Radioanalytical and Nuclear Chemistry 252, 315-325.

Suter, M., Döbeli, M., Grajcar, M., Müller, A., Stocker, M., Sun, G., Synal, H.-A., Wacker, L., 2007. Advances in particle identification in AMS at low energies. Nuclear Instruments and Methods B 59, $165-172$.

Tims, S.G., Hancock, G.J., Wacker, L., Fifield, L.K., 2004. Measurements of $\mathrm{Pu}$ and $\mathrm{Ra}$ isotopes in soils and sediments by AMS. Nuclear Instruments and Methods B 223-224, 796-801.

Vockenhuber, C., Ahmad, I., Golser, R., Kutschera, W., Liechtenstein, V., Priller, A., Steier, P., Winkler, S., 2003. Accelerator mass spectrometry of heavy long-lived radionuclides. International Journal of Mass Spectrometry 223-224, 713-732.

Wacker, L., Chamizo, E., Fifield, L.K., Stocker, M., Suter, M., Synal, H.A., 2005. Measurement of actinides on a compact AMS system working at $300 \mathrm{kV}$. Nuclear Instruments and Methods B 240, 452-457.

Wallner, C., Faestermann, T., Gerstmann, U., Hillebrandt, W., Knie, K., Korschinek, G., Lierse, C., Pomar, C., Rugel, G., 2000. Development of a very sensitive AMS method for the detection of supernovaproduced longliving actinide nuclei in terrestrial archives. Nuclear Instruments and Methods B 172, 333-337.

Winkler, S., Ahmad, I., Golser, R., Kutschera, W., Orlandini, K.A., Paul, M., Priller, A., Steier, P., Valenta, A., Vockenhuber, C., 2004. Developing a detection method of environmental ${ }^{244} \mathrm{Pu}$. Nuclear Instruments and Methods B 223-224, 817-822.

Wyse, E.J., Lee, S.H., Rosa, J.L., Povinec, P., Mora, S.J.D., 2001. ICPsector field mass spectrometry analysis of plutonium isotopes: recognizing and resolving potential interferences. Journal of Analytical Atomic spectrometry 16, 1107-1111. 
Zhao, X.-L., Nadeau, M-J., Kilius, L.R., Litherland, A.E., 1994a. The first detection of naturally-occurring ${ }^{236} \mathrm{U}$ with accelerator mass spectrometry. Nuclear Instruments and Methods B 92, 249-253.

Zhao, X.-L., Nadeau, M.-J., Garwan, M.A., Kilius, L.R., Litherland, A.E., 1994b. Radium, actinides, and their molecular negative ions from a cesium sputter ion source. Nuclear Instruments and Methods B 92, 258-264.

Zhao, X.-L., Kilius, L.R., Litherland, A.E., Beasley, T., 1997. AMS measurement of environmental U-236. Preliminary results and perspectives. Nuclear Instruments and Methods B 126, 297-300. 